\title{
UMA PANORÂMICA DA GENTE RICA NO despontar do SÉculo XX: José Agudo ENTRETECe CENAS DA VIDA PAULISTANA
}

An overview of rich people at the dawn of the 20th century: José Agudo weaves scenes from São Paulo life

\section{Christini Roman de Lima ${ }^{1}$ \\ ${ }^{1}$ Universidade Presbiteriana Mackenzie. São Paulo, SP, Brasil. \\ E-mail: christiniroman@gmail.com}

\section{RESUMO}

José Agudo retrata a cidade de São Paulo em seu processo inicial de modernização, apresentando as cenas paulistanas através da lente dos “donos do poder”, ou seja, dessa Gente rica que intitula a obra. A narrativa, no entanto, é entretecida pelas tintas galhofeiras e mordazes de seu autor.

PALAVRAS-CHAVE: São Paulo; ricos; modernização.

\section{ABSTRACT}

José Agudo represents the city of São Paulo in its initial modernization process, presenting São Paulo scenes through the lens of the "owners of power", that is, of those rich people who entitle the work. The narrative, however, is woven by its author's acerbic mockery and biting paints.

KEYWORDS: São Paulo; rich; modernization.
SUBMETIDO: 25.11 .2021

ACEITO: 01.12.2021

\section{COMO CITAR:}

LIMA, Christini Roman de. Uma panorâmica da gente rica no despontar do século XX: José Agudo entretece cenas da vida paulistana. Revista Brasileira de Literatura Comparada,v.24,n.45,p.126-130, jan./abr., 2022. doi: https:// doi.org/10.1590/2596$304 \times 20222445 \mathrm{cl}$ http:// www.scielo.br/rblc https://revista.abralic.org.br

\footnotetext{
* Resenha de: AGUDO, José. Gente rica: cenas da vida paulistana. Posfácio Walnice Nogueira Galvão. São Paulo: Chão Editora, 2021. 199 p.
} 


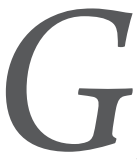

ente rica é uma sátira sobre a elite de São Paulo do início do século XX, como o próprio subtítulo destaca, publicada por José Agudo em 1912 e relançada pela Chão Editora, em 2021, com posfácio de Walnice Nogueira Galvão. José Agudo seria, conforme Galvão (2021), pseudônimo de José da Costa Sampaio, autor de quem se tem parcas informações. Sabe-se, entretanto, que fora cronista, romancista e professor de contabilidade, e produzira uma série de romances entre os anos de 1912 e 1920, romances esses que "buscaram retratos instantâneos e humorísticos da belle époque paulista” (SALIBA, 2005, p. 104). Gente rica seria a primeira dentre as crônicas paulistanas produzidas pelo autor. Seguem-se a ela Gente audaz, de 1913, O Dr. Paradol e seu ajudante, do mesmo ano, Pobre rico!; Cartas d'Oeste, também de 1913; e A pedra que fala, de 1920 (SALIBA, 2005).

Gente rica apresenta uma narrativa fragmentária, em que cada capítulo pode ser lido de forma independente, mas que compõe o conjunto das cenas a que o subtítulo alude e, mais especificamente, dá a ver os "medalhões" paulistas e a relação que eles travavam entre si e com a cidade em seu processo inicial de modernização. O romance é segmentado em onze capítulos, todos intitulados com elementos musicais, compondo uma peça que inicia com o "Prelúdio" e é finalizada por "Grande Concertante". No "Prelúdio", José Agudo introduz a nota em relação à composição da obra: pensava em fazer uma "epopeia da abastança” (p. 11), mas limitou-se a escrevê-la em prosa como um "elogio da riqueza” (p. 11):

muito justo me parece que os ricos pelos ricos sejam lidos.

Este livro é deles e para eles.

Aceitai, pois, ó caríssimos ricos! - este modesto produto dos meus ócios (...). (p. 11).

O romance, narrado em terceira pessoa, tem como protagonista Juvenal de Faria Leme, uma personagem ácida que escrevia para jornais e algumas revistas, era descendente de bandeirantes, mas não se ufanava de sua ancestralidade, ao contrário, envergonha-se: "jactar-se de descender dos ousados bandeirantes [era] o mesmo que honrar-se se ser neto ou bisneto de bandidos e ladrões” (p. 31), destaca ele. Do mesmo modo, Juvenal, que assinava Juvenal Paulista em seus escritos, escarnecia da sociedade abastada da qual fazia parte. Galvão (2021) aponta que "na personagem autônoma divisa-se um portavoz do autor" (p. 154).

O enredo do romance centra-se na formação de uma “Mútua Universal”, ou seja, uma associação oligárquica entre um grupo de sujeitos com a finalidade de instituir uma pensão para os participantes: treze homens pertencentes às classes abastadas de São Paulo. Além de Juvenal de Faria, o grupo é formado por Leivas Gomes, Gustavo da Luz, Archanjo Barreto, Jeronymo Magalhães, Adelino Silveira, Julio Marcondes, Orthépio Gama, Coronel Rogerio Lopes e seu filho Zezinho, Alexandre Rossi, Claro da Silva, barão de Athayde e Araújo Reis.

O foco narrativo se volta às personagens de Juvenal Leme e de Leivas Gomes. Leivas Gomes era engenheiro, apontado pelo narrador como um "self-made man", casado com a filha de um importante fazendeiro, escrevia em jornais e revistas, e era "vítima da paixão das cadeiras eletivas" (p. 77). Todos os elementos da Mútua, no entanto, são retratados como caracteres abjetos e frívolos, retratos esses atravessados pelo humor escarninho do narrador.

Assim, a descrição dos participantes da Mútua Universal é permeada pelo elemento cômico que caracteriza os tipos sociais da elite a que o texto se reporta. O médico Gustavo Luz é apresentado como um homem de estilo hiperbólico e generalizador, especialista em medicina, agronomia e zootecnia. 
Arcanjo Barreto é uma das mais sólidas fortunas (hereditárias) de São Paulo, a quem a natureza não teria sido pródiga nem no físico, nem no intelecto. Jeronymo de Magalhães era visto pela opinião corrente como um capoeira, e, além disso, teria angariado sua renda casando com a credora inicial de seus negócios. Adelino Silveira, que teve a ideia da nova mútua, de simples farol de hotel, tornouse um "herdeiro presuntivo da quarta parte da fortuna do sogro". O comendador Julio Marcondes, descendente de Aimbiré e de um sargento que testemunhara "de oitiva" o Grito do Ipiranga, não tinha inteligência notável e não conseguira "bacharelar-se como todo paulista que se preza" (p. 50); fundara uma revista, escrevera uma peça fantástica e considerava-se "um dos membros da grande falange dos intelectuais brasileiros, que ele classificava muito comovidamente em beletristas e cientistas" (p. 51) e, para mais, desenvolvera um método cadastral de possíveis matrimônios rentáveis, método com o qual progredira socialmente.

As demais personagens não são menos caricatas. O deputado francófilo Orthépio Gama era o "Trimalcião dos campos do Ipiranga" (p. 56). O coronel Rogerio Lopes, proprietário de uma grande fábrica de tecidos e de fazendas de café, fora candidato a um alto cargo, gastando muito dinheiro em campanha, e acabou preterido pelos amigos políticos, a quem vilipendiava verbalmente - pois "quanto às escrituras era uma lástima: - ou não as escrevia, ou quando as assinava de cruz, era uma verdadeira epidemia de riso em todos que as liam" (p.58).Já seu filho, o dr. Zezinho, era bacharel, mas não advogava, frequentava o Cassino e era habitué "dessas pensões que não tem hora para fechar" (p. 59); na época dos estudos fora apontado pelos colegas como "um ilustre bacharel em roupas!" (p. 61), tal foi o vulgar desempenho acadêmico. De seu lado, Alexandre Rossi, que viera da Itália com o propósito de "gozar a América" (p. 67), estabelecera sociedade - industrial e também em relação à bela mulher com quem casara - com dr. Claro da Silva, um influente deputado conhecido pela "nevrose erótica" que alimentava. O barão de Athayde, por sua vez, era herdeiro da exploração escravista. Em criança, montava a cavalo nos escravizados com a aprovação, acompanhada de risadas benevolentes, por parte da família. Sexagenário, o barão fazia caridade, propagandeava e descontava-a cobrando a mais dos inquilinos de algumas de suas propriedades. Por fim, tem-se o poeta original, dr. Araújo Reis, "o mais completo exemplo vivo da perfeita conciliação de um peregrino talento com o caráter mais abjeto" (p. 73).

Ao término da caracterização das personagens, o narrador destaca que não se poderia conciliar maior e melhor número de indivíduos, os quais contribuiriam para o "completo êxito da nova empresa. Nem escolhidos a dedo" (p. 72):

Aufeririam proventos? É possível. Mas - que diabo! - dinheiro parado não rende. É preciso estabelecerse a circulação porque a circulação é a vida.

Além disso, essa gente precisava de qualquer ocupação, para não apodrecer no ócio dissolvente. (p. 72).

No livro de Agudo (2021) há, portanto, uma contundente crítica aos “donos do poder" paulistano, ao bacharelismo, ao desejo de nomeada - à la Brás Cubas - eà frivolidade caracterizadas nas personagens do autor. O protagonista dessa Gente rica paulistana, tal qual o defunto autor fluminense, também versava em torno de estapafúrdias teorias, como a "teoria hidráulico-econômica" sobre a circulação da riqueza, em que associava os homens a bombas, separando-os em "aspirantes" e "prementes" e, entre os dois, os "aspirantes-prementes". Os "aspirantes" elevariam o dinheiro até o nível deles; os "prementes" o pressionariam até o esguichamento "em jactos confortadores" (p. 30); já os "aspirantes-prementes" elevariam o dinheiro até ele alcançar patamares superiores. 
No plano espaço-temporal do romance, veem-se os primeiros passos rumo à moderna São Paulo, atual centro financeiro do país. A cidade se desenha nos passeios das personagens: suas ruas, seus bares, os pontos de encontro, a poeira levantada pelos automóveis que começavam a circular, os bondes, as regatas no Tietê, os migrantes que chegavam tanto da Europa, como de outras partes do país. A São Paulo vista pelas lentes de Gente rica é a cidade da passagem de um século para outro, que se descortinava no limiar de pujança, veem-se os primeiros passos da cidade que logo se tornaria o eixo econômico e cultural do cenário nacional.

Esse limiar situa-se, portanto, na fronteira entre a carroça e o automóvel e que, ao mesmo tempo, separa e limita, permitindo o contato e aproximação entre dois períodos tão distintos como o século XIX e o XX, com suas modificações técnicas, sociais e culturais ensejando seu alvorecer. Juvenal vai criticar, em certo momento - apontando, com isso, aspectos de sua personalidade conservadora - $\mathrm{o}$ desenvolvimento da cidade rumo ao universo de concreto e aço que já era realidade nos Estados Unidos:

—Digo, meus caros, que S. Paulo não é mais o antigo burgo de estudantes e beatas. Aqui já se pensa um pouquinho, meus amigos. Não há só quem atropele e estropie os transeuntes com automóveis disparados, nem quem pense que a nossa prosperidade arquitetônica consiste somente na macaqueação das pavorosas almanjarras de ferro, tijolo e cimento, que são os arranha-céus norte-americanos... (p.98).

O romance, para mais, não abre espaço para além de seus protagonistas, dos homens de posses que compõe a trama. Entretanto, nas linhas de Gente rica vislumbra-se as consequências da escravização findada há vinte e três anos. O preconceito tanto do narrador, quanto do protagonista da história demonstra que o descaso e a benevolência dos senhores escravocratas para com a violência simbólica e física sofrida pela população negra e escravizada se mantinha presente na mentalidade desse estrato social, mesmo daqueles ditos mais progressistas. Percebe-se, nos entrechos do romance, o menosprezo dessa sociedade que relega aquela parcela da população à margem e que, ao mesmo tempo, se propunha trazer braços europeus para o trabalho nos campos. A visão preconcebida e discriminatória mostra-se patente em algumas passagens da obra:

(...) porque os libertos abandonavam em massa o serviço agrícola, para dissolverem a sua já miserável raça na aguardente, que bebiam sem medida, e na indolência produzida pela mais desbragada ociosidade de que há notícia na história dos países novos e de incomensuráveis recursos como é o nosso.

Aqui, não. Para substituir o braço servil, grandes levas de imigrantes europeus tinham vindo à custa dos cofres públicos; e se essa substituição foi ou não proveitosa para nós e para os imigrantes, di-lo mais alto do que todos os argumentos o estado atual da nossa lavoura e a prosperidade real, positiva e palpável da grande maioria desses eficazes auxiliares do nosso progresso. (p. 22).

O romance de João Agudo (2021) apresenta um contexto em transição em que o poder, aos poucos, migrará das mãos desses antigos herdeiros ou proprietários (fruto de casamentos rentáveis com famílias importantes) para os imigrantes que adentravam o país no período em que a obra transcorria. Gente rica é, portanto, retrato de uma época, de uma parcela da população e de uma cidade. Cabe salientar que o posfácio de Walnice Nogueira Galvão é um norte nesse passeio pelo tecido da história e da literatura do período, assim como dos fios que entretecem as Cenas da vida paulistana dispostas pela mão desse malevolente autor. 


\section{REFERÊNCIAS}

AGUDO, José. Gente rica: cenas da vida paulistana. Posfácio Walnice Nogueira Galvão. São Paulo: Chão Editora, 2021. 199 p.

GALVÃO, Walnice Nogueira. Pelos interstícios do cânone. In: AGUDO, José. Gente rica: cenas da vida paulistana. Posfácio Walnice Nogueira Galvão. São Paulo: Chão Editora, 2021. p. 133-191.

SALIBA, Elias Thomé. Aventuras e desventuras de José Agudo, um cronista da Paulicéia na belle époque. Revista USP, São Paulo, v. 63, p. 102-109, set./nov. 2004. Disponível em: https://doi.org/10.11606/ issn.2316-9036.v0i63p102-109. Acesso em: 17 nov. 2021. 